\title{
Modelos explicativos em Saúde Coletiva: abordagem biopsicossocial e auto-organização
}

\author{
I ${ }^{1}$ Rodolfo Franco Puttini, ${ }^{2}$ Alfredo Pereira Junior \\ ${ }^{3}$ Luiz Roberto de Oliveira I
}

Resumo: A complexidade do processo saúdedoença tem ensejado a proposição de uma diversidade de modelos explicativos. Fazemos uma breve revisão dessas propostas, confrontando três perspectivas: o modelo oriundo da Medicina do século XIX, a lógica da História Natural da Doença e o debate epidemiológico no contexto da Medicina Social latino-americana. Tomando-se como referência teórica a ideia de causalidade circular presente na teoria da auto-organização, propomos que os fatores causais privilegiados em cada um dos modelos explicativos acima não seriam conflitantes. Uma noção-chave para se pensar o processo de autoorganização biopsicossocial é o "efeito baldwiniano", que descreve uma relação dialética ou coevolutiva entre processos naturais e socioculturais.

> Palavras-chave: processo de saúde-doença; autoorganização; coevolução; epistemologia das ciências da saúde.

\author{
1 Professor Assistente Doutor, \\ Departamento de Saúde \\ Pública, Faculdade de Medicina \\ de Botucatu, UNESP. Endereço \\ eletrônico: puttini@fmb. \\ unesp.br \\ 2 Professor Adjunto, \\ Departamento de Educação, \\ Instituto de Biociências, UNESP, \\ pesquisador do Programa de \\ Pós-Graduação em Saúde \\ Coletiva do Departamento de \\ Saúde Pública da FMB-UNESP. \\ Endereço eletrônico: apj@ibb. \\ unesp.br \\ ${ }^{3}$ Professor Assistente \\ Doutor, Departamento de \\ Saúde Pública, Faculdade de \\ Medicina de Botucatu, UNESP \\ pesquisador do Programa de \\ Pós-Graduação em Saúde \\ Coletiva do Departamento de \\ Saúde Pública da FMB-UNESP. \\ Endereço eletrônico: Iuizoliv@ \\ fmb.unesp.br
}

Recebido em: 03/08/2009. Aprovado em: 30/04/2010. 
Introdução

Uma nova compreensão de determinantes da saúde só poderá emergir se houver um diálogo entre as ciências humanas e as ciências da vida. Este diálogo não poderia deixar de ser perturbador e incômodo, pois supóe que os pesquisadores de cada disciplina repensem os fundamentos de seus trabalhos, que aceitem trabalhar com outros métodos, que encarem horizontes temporais diferentes e consequentemente modifiquem a maneira de conceber os fenômenos que estudam. Contandriopoulos (1998)

No contexto acadêmico, voltado para o ensino, ou no campo da prática profissional da saúde, o uso que fazemos dos modelos teóricos para conhecer, explicar e compreender o fenômeno da saúde e da doença tem provocado uma produção de conhecimentos interdisciplinares entre as ciências da vida e as ciências humanas. De modo geral, a epígrafe acima representa a preocupação de encontrar saídas para dificuldades do diálogo conceitual e definição de saúde e doença entre essas áreas do conhecimento (MINAYO, 2003). Na prática da Saúde Pública, uma concepção estreita da causalidade (BARATA, 1997) e o reducionismo científico (PAUL, 2005) são apresentados como aspectos epistemológicos que dificultam tal diálogo.

Historicamente, observamos uma hegemonia das ciências biomédicas no contexto da Saúde Coletiva, seja nas definições de saúde e de doença, seja na explicação dos fatores envolvidos nos processos patológicos. Torna-se inadequado, nesta lógica, explicar tais fenômenos por meio de determinações próprias da estrutura social de uma sociedade. O objetivo do presente ensaio, ao rever três modelos teóricos explicativos do processo saúde-doença, é discutir as condiçōes de possibilidades para o diálogo interdisciplinar em Saúde Coletiva. Temos em vista sugerir que a interdisciplinaridade já existente em Saúde Coletiva poderia se dirigir para a elaboração de modelos transdisciplinares (ALMEIDA FILHO, 2005).

\section{$\mathrm{O}$ modelo biomédico}

O modelo biomédico clássico denota uma compreensão dos fenômenos de saúde e doença com base nas ciências da vida, a partir da Biologia. Nessa abordagem, a doença é definida como desajuste ou falta de mecanismos de adaptação do organismo ao meio, ou ainda como uma presença de perturbações 
da estrutura viva, causadoras de desarranjos na função de um órgão, sistema ou organismo. $\mathrm{Na}$ era do progresso científico da bacteriologia, entendia Claude Bernard (BERNARD, 1865) que sempre existiria um mecanismo etiopatogênico subjacente às doenças. As doenças são definidas pela ação de agentes patogênicos; e o agente etiológico será entendido sempre como o causador de toda doença. Ao longo do tempo, o modelo biomédico foi assimilado pelo senso comum, tendo como foco principal a doença infecciosa causada por um agente.

Diante da etiologia da doença, o modelo biomédico adota uma lógica unicausal, também designada lógica linear, procurando-se identificar uma causa a qual, por determinação mecânica, unidirecional e progressiva, explicaria o fenômeno do adoecer, direcionando a explicação a se tornar universal (LUZ, 1988). É nessas condiçôes epistemológicas que o modelo biomédico, nas ciências da saúde, tende a reproduzir conhecimentos universais relativos aos seres humanos.

As reflexões críticas de Georges Canguilhem sobre a noção de normalidade (CANGUILHEM, 1995) se dirigem contra tal modelo unicausal. Com base no conhecimento médico produzido no século XIX, Canguilhem criticou a aplicação do conhecimento biológico para a medicina, mostrando como o conhecimento biomédico desse período esteve equivocadamente ligado a valores atribuídos à normalidade e à patologia nos fenômenos da vida. O filósofo propôs adotar o conceito de normatividade da vida, como uma resposta aos conflitos epistemológicos gerados naquela época, objetivando superar a dicotomia entre o "normal" e o "patológico".

$\mathrm{Na}$ visão epidemiológica de base biomédica, pode-se definir a saúde populacional pela presença ou ausência de fatores de risco. Desse raciocínio decorre o conceito de saúde da coletividade como ausência de doenças (BOORSE, 1977 apud ALMEIDA FILHO, 2000, p. 6). A crítica fundamental ao modelo biomédico aplicada para a saúde da população tem por base a ocorrência de correlaçôes (observadas na clínica médica) dos fenômenos epidemiológicos com aspectos da organização política e social da sociedade humana.

Classicamente, o modelo unicausal toma por base o mecanicismo, mais tarde incorporando aspectos da biologia evolucionista. Sabemos da influência da ideologia organicista na construção da sociologia científica de Émile Durkheim e no desenvolvimento do evolucionismo social de Herbert Spencer, esquemas teóricos de época que influem, até a atualidade, nas políticas públicas. Contra tal paradigma, o campo da Saúde Coletiva apresenta-se na história da ciência da saúde como modelo 
metateórico contra-hegemônico. Por exemplo, vemos tais preocupações nos estudos históricos e filosóficos sobre a clínica médica, proposto pela arqueologia do saber e da genealogia do poder de Michel Foucault (FOUCAULT, 1987), ou ainda, vemos a epistemologia de Luwdwig Fleck no primeiro quartel do século XX (FLECK, 1986) trabalhar em favor de novos paradigmas em saúde.

\section{O modelo da história natural da doença}

Entre as décadas de 1950-70, nasce uma perspectiva da Saúde Coletiva em âmbito mundial. Diante da nova ordem do pós-II Guerra - mais precisamente no contexto da criação política supranacional da Organização das Nações Unidas (ONU) e da Organização Mundial da Saúde (OMS) - o conceito de saúde ganha nova configuração: "saúde é o estado de completo bem-estar físico, mental e social e não mera ausência de moléstia ou enfermidade” (WHO, 1948).

De modo geral, podemos afirmar que o modelo explicativo multicausal delineado por Leavell e Clark (LEAVELL; CLARK, 1976) privilegia o entendimento da saúde como um processo, por meio do conhecimento acumulado do campo científico. Nessa lógica causal, o restabelecimento da normalidade está fundamentado na visão positiva da saúde, que é valorizada pela noção de prevenção sobre as doenças. Ou seja, procedimentos e ações promotoras de saúde e de prevenção de doenças, aplicadas tanto ao indivíduo quanto à coletividade de pessoas acometidas ou não por doenças (transmissíveis ou não-transmissíveis), encontram eco no âmbito do conhecimento da saúde humana.

Enquanto no modelo biomédico (unicausal) o conceito de saúde prevalece na condição lógica exclusivamente em razão da ausência da doença (primordialmente sobre a doença infecciosa), no modelo multicausal, sistematizado por Leavell e Clark (LEAVELL; CLARK, 1976), privilegia-se o conhecimento da história natural da doença. $\mathrm{O}$ conceito de saúde ganha estruturação explicativa proporcionada pelo esquema da tríade ecológica (agente, hospedeiro e meio ambiente). Com esses elementos, o proposto modelo epidemiológico englobaria o modelo biomédico: "conjunto de processos interativos que cria o estímulo patológico no meio ambiente, ou em qualquer outro lugar, passando pela resposta do homem ao estímulo, até as alteraçôes que levam a um defeito, invalidez, recuperação ou morte" (LEAVELL; CLARK, 1976, p. 46). Assim, o conhecimento epidemiológico ganha novo método para delineamento sistemático 
da prevenção e controle de doenças nas populações, uma vez expostos dois domínios possíveis de promoção da saúde: o meio externo, de onde interagem determinantes e agentes em relação com o meio ambiente; e o meio interno, onde se desenvolve a doença no organismo vivo. Os fatores externos contribuem para o adoecimento e estão caracterizados pela natureza física, biológica, sociopolítica e cultural. O meio interno é o lugar individual onde se processam modificaçôes químicas, fisiológicas e histológicas próprias da enfermidade no indivíduo doente - enfim, onde atuam fatores hereditário-congênitos, aumento/diminuição das defesas e alteraçôes orgânicas.

O processo natural da doença, assim instalado no corpo humano, evolui em dois períodos consecutivos:

1) O período pré-patogênico, em que a patologia ainda não está manifesta, os determinantes intrínsecos ao sujeito estruturam disposições ao adoecimento: são os agentes físicos e químicos, biopatógenos, agentes nutricionais, agentes genéticos, determinantes econômicos, culturais e psicossociais. Esse período etiológico está também designado no nível de atenção primária, porque podemos atuar coletivamente agindo com ações de prevenção, promovendo a saúde (com educação, por exemplo) e fazendo a proteção específica da saúde (por exemplo, com vacinas).

2) O período patogênico, no qual já se encontra ativo o processo patológico, período em que a doença se processa naturalmente no corpo do ser humano, iniciamse as primeiras alterações no estado de normalidade, pela atuação de agentes patogênicos. Seguem-se perturbações bioquímicas em nível celular, provocando distúrbios na forma e função de órgãos e sistemas, evoluindo para as seguintes possibilidades: defeito permanente (sequela), cronicidade, morte ou cura.

Almeida Filho e Rouquayrol (2002) afirmam que, embora o modelo multicausal da história natural das doenças tenha por foco reconhecer no processo saúde-doença múltiplas determinaçôes - e por isso mesmo é que poderia representar um avanço na história da epidemiologia -, é forte a influência que recebe do hegemônico modelo biomédico. Para os autores, há uma tendência em valorizar de modo secundário os determinantes sociais, sobre a qual fazem a seguinte crítica: a) a determinação dos fenômenos da saúde não se restringe à causalidade das patologias (patogênese); b) a história natural das doenças de maneira nenhuma é tão somente natural. 


\section{O modelo da determinação social da doença}

Desde a década de 1960, em paralelo ao progresso técnico e tecnológico na Medicina e atividade médica, alguns intelectuais, principalmente latinoamericanos pensaram a Medicina Social como campo de novos saberes e conhecimentos, no contrafluxo da hegemonia do modelo biomédico. A proposta de um novo conceito de Epidemiologia foi elaborado a partir da crítica à insuficiência da epidemiologia tradicional em abordar a saúde como um fenômeno radicado na organização social.

Para Breilh \& Granda (1986), o raciocínio epidemiológico tradicional do processo saúde-doença dirige o olhar para os transtornos biológicos e/ou psíquicos existentes em um dado conjunto de indivíduos e para as respectivas características individuais, sem, contudo, a preocupação de considerar o que pertence estritamente ao âmbito biológico e o que pertence ao social. Nessa forma de observação, não importa a posição ocupada pelos indivíduos no processo produtivo. Para os autores, classe social é uma categoria que representa uma condição a ser utilizada, inicialmente, na exploração epidemiológica de uma coletividade. Isso significa dizer que a condição social é um pressuposto primordial para o conhecimento epidemiológico. Interessa, portanto, sistematizar e estudar com maior especificidade os variados processos que resultam em condições de vida e saúde numa dada coletividade. Importa trazer à tona conhecimentos causais da reprodução social das doenças e da saúde ligados ao processo das classes sociais e descobrir valores e contravalores relacionados à saúde e à vida dos indivíduos de uma população.

Esse conjunto inter-relacionado de processos sociais e de morbidade de uma classe foi denominado de perfil epidemiológico (BREILH, 1991). Esse autor define epidemiologia como "ciência que tem por objeto estudar saúde e doença como processo particular de uma sociedade" (BREILH, 1991, p. 56). Funda-se, assim, outro modo de investigação epidemiológica enquanto praxis emancipadora (BREILH, 2003). Pela vertente marxista, trata-se da crítica à epidemiologia clássica, direcionada à investigação no campo da saúde, cuja metodologia privilegia a organização como substrato de perfis ou padrões típicos de saúde e doença.

Com a mesma preocupação de época em busca da fundamentação da Medicina Social como campo de conhecimento, Sergio Arouca (AROUCA, 2003) reforçou a crítica ao modelo clássico da epidemiologia biomédica através da desconstrução do dilema preventivista contemplado no modelo epidemiológico de Leavell e Clark 
(LEAVELL; CLARK, 1976). Considerando a definição de saúde nessa referência,

Arouca demonstrou o reducionismo, do ponto de vista epistemológico, da prática médica naquela versão preventivista. Historicamente, desde a década de 1970, as críticas à epidemiologia clássica ganharam força significativa no movimento sanitarista brasileiro e fundamentaram a constituição de um novo campo de conhecimento, o da Saúde Coletiva. Essa reflexão e construção teórica repercutiram, também, nos movimentos sociais e lutas políticas dos últimos 25 anos. No Brasil, um grande movimento pela Reforma Sanitária tem lugar e se faz presente desde a Constituinte de 1988. A Constituição Federal estabelece a saúde como direito de todos e dever do Estado e as bases fundadoras do SUS, o Sistema Único de Saúde.

No entanto, sobressaem questôes lógicas dos modelos explicativos de saúde e doença no contexto da construção democrática em saúde: se o modelo multicausal tem inspirado a promoção de saúde para o planejamento nos variados níveis de atenção, complexidade e organização do sistema de saúde, como reorganizar as ações médicas voltadas para a atenção primária da população? Ou ainda mais, como utilizar única e exclusivamente o modelo multicausal para o planejamento em saúde sem se erradicar a pobreza e dirimir a exclusão social, ou sem cair na ideologia da medicalização da sociedade (TESSER, 2006)? Estamos propondo pensar os modelos explicativos em Saúde Coletiva também em vista das possibilidades de reorganização do sistema público de saúde em intersecção com a reorganização ética da sociedade civil.

\section{Complexidade, auto-organização e sistemas sociais}

À consideração das cadeias causais lineares - ou de conexôes lógicas lineares entre princípios e consequências -, vem se acrescentar a consideração de fenômenos caracterizados por cadeias causais "circulares", envolvendo diferentes níveis de organização de um mesmo sistema complexo, nas quais os efeitos das atividades num determinado nível organizacional afetariam os demais níveis, e vice-versa. Deste modo, o desenvolvimento de um processo de transformação, em um sistema complexo, afetaria as condições geradoras deste mesmo processo. Entendemos que o sistema populacional humano, em cujo âmbito se desenvolvem os processos de saúde-doença, seria um sistema deste tipo, no qual os fatores biológicos, sociais e culturais se influenciam mutuamente, de modo dialético ou coevolutivo, como discutiremos a seguir. 
Em que medida referimos a abordagem da "causalidade circular" no âmbito biopsicossocial? Afirmamos inicialmente as preocupações gerais formuladas do campo das Ciências Sociais, particularmente da abordagem funcionalista e neofuncionalista que tem em Talcoot Parsons seu representante antigo e em Niklas Luhmann o contemporâneo com a aplicação da Teoria da Autopoiese às Ciências Sociais.

Parsons (1964 apud ABEL, 1972) é a marca da sociologia norte-americana no século XX que mantém seu legado atual na referência dos países desenvolvidos do Hemisfério Norte. Isso porque, ao dedicar sua vida à compreensão sistêmica das sociedades humanas, propôs um robusto esquema conceitual e teórico aplicável ao processo de desenvolvimento das sociedades capitalistas no contexto do sistema das economias liberais. Segundo a teoria geral da ação de Parsons, é possível analisar sistemas sociais, tendo por quadro de referência os papéis e o status na sociedade. O status implica direitos enquanto os papéis, obrigações; e o reconhecimento de direitos e obrigações é condição básica para estabilidade de um sistema social. Assim, o objetivo da sociologia de entender qualquer sociedade, para Parsons, está dado pelo decurso da homeostase em um sistema social. Normas e valores são internalizados na medida em que são compartilhados por uma coletividade, que pressupõe condutas com responsabilidade moral. Por suas palavras:

a integração de um conjunto de padrões de valor comuns com a estrutura internalizada da disposição de necessidade das personalidades constituintes é o fenômeno central da dinâmica dos sistemas sociais. Pode-se dizer que a estabilidade de qualquer sistema social, que não seja um efêmero processo de interação, ser dependente em certo grau de tal integração, constitui o teorema dinâmico fundamental da Sociologia (PARSONS, 1964 apud ABEL, 1972, p. 138).

Nesse contexto, cabe uma crítica à tendência sociológica da biossociologia nas ciências sociais (LACERDA, 2009). Pois, a tendência de pensar o funcionamento das sociedades humanas de um ponto de vista biológico e global coloca à vista a questão da Sociologia funcionalista a serviço dos países centrais no quadro da economia mundial, que certamente tende a valorizar uma crescente lucratividade dos setores produtivos, como o da saúde, em detrimento de consequências sociais sem precedentes nos países periféricos do planeta. Afora as contribuições teóricas dessa abordagem funcionalista-estrutural, pretendemos valorizar uma teoria crítica aplicada ao campo da saúde que viabilize pensar o destino da natureza humana no processo de desenvolvimento social e econômico, balizado por 
princípios éticos e bioéticos dos direitos humanos (GARRAFA, 2005). Estamos

entendendo que em nosso tempo contemporâneo essas novas perspectivas teóricas devem orientar soluções para problemas de saúde pública mundial, que persistem e emergem nos países do Hemisfério Sul (GARRAFA; PORTO, 2003).

Luhmann (1986) procurou aplicar a teoria autopoiética de Humberto Maturana e Francisco Varela no contexto das ciências sociais. Sistemas autopoiéticos são definidos como aqueles que produzem seus componentes, autogerando e realizando a própria rede que os produz e constitui, no espaço no qual eles existem (LUHMANN; DE GIORGI, 1993). Nesse contexto, podemos melhor aplicar a noção de causalidade circular, presente na formulação original dos biólogos chilenos, que constituiria o princípio de funcionamento não apenas de células, sistema nervoso ou organismos biológicos vegetais ou animais, mas igualmente dos sistemas sociais (COSTA, 2009).

Entre os sistemas vivos, dotados de mentalidade, e os sistemas sociais, estabelecese, por meio da linguagem, o que Luhmann denomina um "acoplamento estrutural”. Ambos produzem, respectivamente, pensamentos e comunicações, que não são operativamente intercambiáveis, mas produzem "ruídos". Uma vez percebidos e internalizados pelo respectivo sistema, tais "ruídos" servem para reorientar suas operações internas (COSTA, 2009).

Como atuam em fechamento operacional, a possibilidade de os sistemas vivos se observarem mutuamente deriva da abertura cognitiva da linguagem (LUHMANN, 1986). Sistemas vivos operacionalmente separados, mas unidos pela linguagem, passam a formar sistemas sociais complexos. O que distingue basicamente a autopoeise biológica da social é a composição dos respectivos sistemas. No primeiro caso, os elementos sistêmicos são células ou organismos vivos, e no segundo, são atos comunicativos (COSTA, 2009). O fechamento operacional implica que a produção de novos elementos é dependente das operações precedentes do sistema. Por sua vez, essa produção servirá de base para as operações futuras do sistema. Deste modo, o sistema social engendra comunicações a partir de uma alteração dos estados de cognição dos indivíduos. Por sua vez, os indivíduos alteram seus estados cognitivos a partir de uma percepção das comunicações efetuadas no âmbito do sistema social (LUHMANN; DE GIORGI, 1993).

Segundo Costa (2009), a autopoiese social processa-se mediante diversas operaçôes seletivas de sentido, por meio das quais o sistema reduz a complexidade 
do ambiente e estabelece uma forma de mediar a abertura cognitiva. Como o sistema é autorreferente (é capaz de se incluir em suas operações cognitivas), "deve definir seus próprios contornos a partir da distinção sistema/ambiente e também selecionar entre a continuidade da autopoiese ou não... O sistema decide, portanto, sobre sua sobrevivência" (COSTA, 2009). Para sobreviver, o sistema social deve continuar a comunicar (LUHMANN, 1982, p. 82). Por meio da autorreferência, o sistema atua de forma autônoma.

Do ponto de vista histórico, podemos afirmar, no campo científico, que do final do século XVIII até o final dos anos 1950, a tendência dominante era a das explicações reducionistas, em que os processos causais eram enfocados num único plano de análise, sob a égide de uma disciplina científica privilegiada. Nos últimos anos, entretanto, detecta-se uma tendência entre os cientistas de rejeição da concepção de ordem como sendo um "dever ser", uma exigência da natureza ou da sociedade, que se pudesse exaurir pela abordagem reducionista. Nesse sentido, situamo-nos diante do "alargamento do horizonte da racionalidade", como observou Roberto Cardoso de Oliveira no campo da antropologia brasileira (OLIVEIRA, 1995). Assim, a ênfase sobre a capacidade de auto-organização dos sistemas físicos, biológicos e humano-sociais parece assinalar o advento de um novo paradigma filosófico e científico (KELLER, 2008; 2009). O conceito de AO se refere a processos espontâneos que ocorrem em sistemas semifechados, em resposta a perturbações de origem externa.

Dentre os estudos contemporâneos de fenômenos de auto-organização (AO), destacamos a teoria proposta por Michel Debrun (DEBRUN, 1996). Ele distingue entre dois tipos de $\mathrm{AO}$. Na primária, um sistema - i.e., uma rede de relações se forma, a partir das interações que se estabelecem entre diversos elementos anteriormente independentes entre si. Já na secundária, um sistema já constituído, que seja aberto a interações com seu meio (o que é uma condição necessária, tendo em vista a Segunda Lei da Termodinâmica), passa por transformaçóes organizacionais que decorrem primordialmente de relaçôes intrínsecas (aquelas que são estabelecidas ao longo do tempo, entre os componentes do sistema), e não de uma ação extrínseca (i.e., de fatores externos ao sistema, o que - se fosse o caso - caracterizaria uma hetero-organização).

De acordo com a sugestão feita por Morin (MORIN, 1977), o conceito de $\mathrm{AO}$ alcançaria "além do mecanicismo e do vitalismo", possibilitando a superação 
de limitações daqueles tipos de modelos. Nesta perspectiva, a concepção de normatividade da vida proposta por Canguilhem - uma importante referência para se discutir os conceitos de saúde e doença - emergiria da própria atividade do ser vivo (vide PUTTINI; PEREIRA JUNIOR, 2007), situando-se no plano da AO secundária, na qual um sistema já formado - um organismo vivo estabelece as metas para si, a partir de sua própria atividade ao longo do tempo, partindo de interações entre seus componentes e do sistema do ambiente.

Sugerimos que se desfaça, no plano conceitual, a oposição estanque entre os domínios da realidade biológica e humano-social, enfocando-se então os domínios de intersecção constituídos pelos processos biológicos socialmente moldados, assim como relações humanas embasadas em processos biológicos. Um bom exemplo desta visão advém dos estudos a respeito da plasticidade cerebral, na Neurociência Cognitiva, revelando que práticas culturais (por exemplo, atividades musicais) influenciam a constituição anatômico-fisiológica do cérebro de seus praticantes.

Em termos de processos evolutivos, tal perspectiva transcende os modelos explicativos darwinianos, embora não se contrapondo diretamente a eles (PEREIRA JR. et al., 2004), ao admitirmos a ocorrência do denominado "efeito baldwiniano", que consiste na possibilidade de que padrões de organização social e modos de vida estabelecidos numa sociedade possam influenciar padrões biológicos (inclusive genéticos) das novas geraçōes, ao se tornarem parâmetros que balizam o processo seletivo (DEACON, 1997; STERELNY, 2004).

Como exemplo, citamos uma possível preferência de indivíduos do sexo masculino, de uma determinada formação social, por mulheres de quadris largos, o que levaria a uma maior taxa de reprodução das portadoras desta característica fenotípica, e consequentemente ocorreria, ao longo do tempo, um aumento da frequência dos genes responsáveis por este traço na população. Este tipo de processo, em que um padrão culturalmente estabelecido se torna referência para a evolução biológica, é também utilizado na "seleção artificial" por criadores de plantas e animais, quando desejam ressaltar um determinado traço fenotípico.

\section{Comentários finais}

Embora não seja possível aproximar conceitualmente paradigmas opostos, entendemos a viabilidade do diálogo interdisciplinar entre as Ciências da Vida, 
Ciências Sociais e Epidemiologia, envolvidas na práxis da Saúde Coletiva. A consideração da possibilidade de uma dialética ou processo coevolutivo, em que os diversos tipos de fatores determinantes da saúde-doença se influenciam reciprocamente, abre uma nova possibilidade de entendimento da complexidade biopsicossocial do ser humano. Apostamos na opção transdisciplinar como meio de viabilizar a realização e identificação de múltiplos determinantes do processo saúde-doença e suas interaçõos dinâmicas.

Considerando que o processo coevolutivo no qual estamos inseridos envolveria uma auto-organização do indivíduo e da sociedade humana, engendrando em seu bojo uma intencionalidade intrínseca ao processo, não podemos concluir senão por nossa responsabilidade coletiva frente aos rumos do processo de evolução biológica e histórica, de nossa espécie e do planeta em que vivemos. Partindo dessa perspectiva, adentramos o terreno da ética em saúde, enfatizando os riscos para o futuro da humanidade que podem advir de nossas escolhas presentes (HABERMAS, 2003).

\section{Referências}

ABEL, T. Os fundamentos da teoria sociológica. Rio de Janeiro: Zahar, 1972.

ALMEIDA FILHO, N.; ROUQUARYOL, M.Z. Introdução à epidemiologia. Rio de Janeiro: Editora Médica e Científica, 2002.

ALMEIDA FILHO, N. O conceito de saúde e a vigilância sanitária: notas para a compreensão de um conjunto organizado de práticas de saúde. In: ANVISA. Seminários temáticos permanentes. Brasília: Ministério da Saúde, 2000.

Transdisciplinaridade e o paradigma pós-disciplinar na saúde. Revista Saúde e Sociedade, v. 14, n. 3, p. 30-50, set-dez 2005.

AROUCA, A.S.S. O Dilema preventivista: contribuição para a compreensão e crítica da medicina preventiva. Rio de Janeiro: Fiocruz, 2003.

BARATA, R.B. Causality and epidemiology. Hist. cienc. saude-Manguinhos, Rio de Janeiro, v. 4, n. 1, 1997.

BERNARD, C. Introduction à l'Étude de la Médecine Expérimentale, 1865. Disponível em: http://classiques.uqac.ca/classiques/bernard_claude/intro_etude_medecine_exp/intro_ etude.html. Acesso em: 01 ago. 2009.

BREILH, J. Epidemiologia: economia, politica e saúde. São Paulo: Hucitec, 1991.

Epidemiologia crítica: ciência emancipadora e interculturalidad. Buenos Aires: Lugar Editorial, 2003. 
BREILH, J.; GRANDA, E. Investigação da Saúde na Sociedade: guia pedagógico sobre um novo enfoque do método epidemiológico. São Paulo: Inst.Saúde/Abrasco, 1986.

CANGUILHEM, G. O normal e o patológico. Rio de Janeiro: Forense Universitária, 1995.

CONTANDRIOPOULOS, A. P. Pode-se construir modelos baseados na relação entre contextos sociais e saúde? Cad. Saúde Pública. Rio de Janeiro, v. 14, n. 1, p. 199-204, jan./mar. 1998.

COSTA, O.R.B. Sobre as causas evolutivas da cognição humana. Dissertação (Mestrado em Filosofia) - Programa de Pós-Graduação em Filosofia. Faculdade de Filosofia e Ciências de Marília: Universidade Estadual Paulista (UNESP), 2009.

DEACON T. The Symbolic Species: The Co-evolution of Language and the Brain. New York: W.W. Norton, 1997.

DEBRUN, M. O Conceito de Auto-Organização. In: DEBRUN, M.; GONZÁLES, M.E.Q.; PESSOA JUNIOR, O. (Org.). Auto-Organização: estudos interdisciplinares. Campinas: Centro de Lógica e Epistemologia/UNICAMP, 1996.

FLECK, L. La génesis y el desarrollo de un hecho científico. Madrid: Alianza Editorial, 1986. FOUCAULT, M. A arqueologia do saber. Rio de Janeiro: Forense-Universitária, 1987.

GARRAFA, V.; PORTO, D. Intervention bioethics: a proposal for peripheral countries in a context of power and injustice. Bioethics, v. 17, n. 5, p. 399-416, 2003.

GARRAFA, V. Inclusão social no contexto político da Bioética. Revista Brasileira de Bioética, v. 1, n. 2, p. 122-132, 2005.

HABERMAS, J. O futuro da natureza humana. São Paulo: Martins Fontes, 2003.

KELLER, E.F. Organisms, machines, and thunderstorms: a history of self-organization. Part One. Historical Studies in the Natural Sciences, v. 38, n. 1, p. 45-75, 2008.

KELLER, E.F. Organisms, machines, and thunderstorms: a history of self-organization. Part Two. Complexity, emergence, and stable attractors. Historical Studies in the Natural Sciences, v. 39, n. 1, p. 1-31, 2009.

LACERDA, A.L.R. Abordagens biossociais na sociologia: biossociologia ou sociologia evolucionista? Rev. Bras. Ci. Soc. São Paulo, v. 24, n. 70, jun. 2009.

LEAVELL, H.; CLARK, E.G. Medicina Preventiva. São Paulo: McGraw-Hill, 1976.

LUHMANN, N. The autopoiesis of social systems. In: GEYER, F.; ZOUWEN, J. (Org.). Sociocybernetic Paradoxes. London: Sage, 1986.

LUHMANN, N.; DE GIORGI, R. Teoría de la Sociedad. Guadalajara: Universidadde Guadalajara, 1993.

LUZ, M.T. Natureza e razão no tempo e no espaço mecânicos. In: Natural, racional, social: razão médica e racionalidade científica moderna. São Paulo: Hucitec, 1988. MINAYO, M.C.S. et al . Possibilidades e dificuldades nas relações entre ciências sociais e epidemiologia. Ciênc. Saúde Coletiva, Rio de Janeiro, v. 8, n. 1, p. 97-107, 2003. 
MORIN, E. O Método I: a natureza da natureza. Lisboa: Publicações Europa-América, 1977. OLIVEIRA, R.C. Antropologia e a crise dos modelos explicativos. Estud. Avançados, v. 9, n. 25, p. 213-228, 1995.

PARSONS, T. The social system. New York: Free Press, 1964.

PAUL, P. Transdisciplinaridade e antropoformação: sua importância nas pesquisas em saúde. Saúde e Sociedade, v. 14, n. 3, p. 72-92, set-dez 2005.

PEREIRA JUNIOR, A. et al. Evolução biológica e auto-organização: propostas teóricas e discussão de dois casos empíricos In: . Auto Organização. Estudos Interdisciplinares 3. Campinas: Unicamp, 2004. P. 21-72 (Coleção CLE, v. 39).

PUTTINI, R.F.; PEREIRA JUNIOR, A. Além do mecanicismo e do vitalismo: a "normatividade da vida" em Georges Canguilhem. Physis: Revista de Saúde Coletiva. Rio de Janeiro, v. 17,n. 2, p. 451-464, 2007.

STERELNY, K. A review of evolution and learning: the Baldwin effect reconsidered. In: WEBER, B.; DEPEW, D. (Ed.). Evolution \& Development, v. 6, n.4, p. 295-300, 2004.

TESSER, C.D. Medicalização social (II): limites biomédicos e propostas para a clínica na atenção básica. Interface - Comunic., Saúde, Educ. Botucatu, v. 10, n. 20, p. 347-62, 2006. WORLD HEALTH ORGANIZATION. Constituição da Organização Mundial de Saúde. Conferência Internacional da Saúde. New York: WHO, 1948. Disponível em: <http:// www.who.int/governance/eb/who_constitution_sp.pdf>. Acesso em: 01 jan. 2008. 


\section{Abstract}

Explanatory models in Collective Health: BioPsycho-Social Complexity and Self-Organization The complexity of the health-disease process has elicited the postulation of a diversity of explanatory models. We make a brief review of the proposals, starting with the biomedical model derived from the 19th century medicine. This model influenced the approach on the natural history of disease, and the debate on epidemiologic models in the context of the LatinAmerican Social Medicine. Broadening the spectrum of the discussion, we introduce the idea of circular causality, proposed by theories of self-organizing systems. We argue that, in a transdisciplinary perspective, these explanatory models are not conflicting. A key notion to understand these classes of concomitant explanatory models is the "Baldwin Effect", describing a dialectic or coevolutionary relation between nature, social organization and culture.

> Key words: health-disease process; self-organization; coevolution, epistemology of health sciences. 